\title{
Study on Properties of Fresh and Hardened Self Compacting Concrete with Varied Percentages of Metakaolin as Mineral Admixture (M40 Grade)
}

\author{
B. Ramyalekha ${ }^{1}$, Dr. V. Mallikarjuna Reddy ${ }^{2}$ \\ ${ }^{1}$ M.Tech (Struct.Engg) Student, Department of Civil Engineering, GRIET, Hyderabad, India. \\ ${ }^{2}$ Professor, Department of Civil Engineering, GRIET, Hyderabad, India.
}

\begin{abstract}
The objective of this paper is to study the properties of fresh and hardened self compacting concrete with varied percentages of metakaolin as mineral admixture (M40 grade). In this study cement is replaced by metakoalin with varied percentages, $20 \%, 22 \%, 24 \%, 26 \%, 28 \%, 30 \%, 32 \%, 34 \%, 36 \%$ \& $38 \%$ with a constant packing factor of 1.14. In the present study, B233 GLENIUM super plasticizer is used. As per the European guidelines for Self-compacting concrete, the workability tests such as slump flow test, V-funnel test and L-box, U-box test were carried out in laboratory. The concrete specimens were cured in the tank for 7 and 28 days and tested for determining the compressive strength and split tensile strength and flexural strength respectively. From the study it is observed that workability and mechanical properties such as Compressive strength. Split tensile strength and Flexural strength test increased with increase in metakoalin up to $30 \%$ and decreased from $32 \%$ to 38\%. Non Destructive Test is also performed to assess the quality of concrete in the hardened state.
\end{abstract}

Keywords: Self Compacting concrete, Metakaolin, super plasticizer, NDT, Fresh and Hardened properties.

\section{Introduction}

Self compacting concrete $(\mathrm{scc})$ is highly engineered concrete with much higher fluidity without segregation and is capable of filling every corner of formwork under its self weight. Thus SCC eliminates the vibration for the compaction of concrete without affecting its engineering properties. In general Self Compacting Concrete results in reduced construction times and reduced noise pollution. Self-compacting concrete (SCC) offers various advantages in the construction process due to its improved quality, and productivity. SCC has higher powder content and a lower coarse aggregate volume ratio as compared to normally vibrated concrete (NVC) in order to ensure SCCees filling ability, passing ability and segregation resistance. If only cement is used in SCC, it becomes high costly, susceptible to be attack and produces much thermal crack. It is therefore necessary to replace some of the cement by additives, to achieve an economical and durable concrete. This study aims to focus on the possibility of use of Metakaolin to improve the properties of SCC

\section{Literature Review}

Hagime Okamura \& Masahiro Ouchi. [1] Investigation for Establishing a rational mix design method and self compact ability testing methods have been carried out from the view point of making SCC a standard concrete. J.M. Justice et al, [2], Investigated the Comparison of two Metakaolins and a Silica Fume Used as Supplementary cementitious Materials. The performance of two metakaolin as supplementary cementitious materials (SCMs) was evaluated at $8 \%$ by weight cement replacement.

Vilas V. Karjinni and Shrishail B. Anadinni. [3] They emphasized on the mixture proportion which is one of the important parameter in the self compacting concrete. They have used modified Nan-su method and obtained mix design in normal grades with different mineral admixtures \& the compressive strength and flow properties of SCC were also studied.

B.B Sabir, S. Wild, J Bai. [4] This paper reviews work carried out on the use of Metakoalin as a partial pozzolanic replacement for cement in mortar and concrete and in the containment of hazardous wastes. The literature demonstrates that Metakoalin is an effective pozzolan which causes great improvement in the pore structure and hence the resistance of the concrete to the action of harmful solutions. On the basis of above studies, an attempt has been made in the present investigation was to study on behavior of self compacting concrete with various percentages of replacement of cement with metakoalin. The modified Nan-su method was used for mix design of SCC along with chemical admixture such as B233 glenium.

\section{Experimental Programme}

An extensive experimental Programme involving the various processes of material testing, mix proportioning, mixing, casting and curing of specimens and testing of specimens were done. The forthcoming sections elaborate the various physical and chemical properties of each material separately. 


\subsection{Materials Used}

The materials used in the preparation of concrete mixes includes cement, fine aggregate, coarse aggregates, metakaolin and Poly carboxylic ether based admixture namely Glenium B233 (brought from BASF) was used to enhance the flow ability of the mixtures. Each material was tested $\&$ its physical properties are described below.

\subsubsection{Cement}

OPC of 53 grade has been used in the study conforming to recommendations stated in IS: 12269-1987. It was procured from a single source and stored.OPC - Ultratech cement was used throughout the experimental work. The physical properties of OPC are tabulated in Table $1 .{ }^{[8]}$

Table 1: Physical properties of Ordinary Portland Cement

\begin{tabular}{|l|l|l|}
\hline S. No & Property & Test Results \\
\hline 1. & Normal Consistency & $30 \%$ \\
\hline 2. & Specific gravity & 2.9 \\
\hline 3. & $\begin{array}{l}\text { Initial setting time } \\
\text { Final setting time } \\
\text { Final setting time }\end{array}$ & $\begin{array}{l}99 \text { minutes } \\
207 \text { minutes }\end{array}$ \\
\hline 4. & Fineness & $1.3 \%$ \\
\hline 5. & Soundness & $2 \mathrm{~mm}$ \\
\hline
\end{tabular}

\subsubsection{Aggregates}

The fine aggregate used was locally available river sand without any organic impurities and the coarse aggregate were used, which was bought from the nearby quarry. Aggregates of $10 \mathrm{~mm}$ were chosen for the experiment which is clean and free from deleterious materials used was conforming to IS: $383-1970$. The physical properties of fine aggregate and coarse aggregate was shown in Table $2^{[9]}$

Table 2: Physical properties of fine aggregate and Coarse aggregate

\begin{tabular}{|l|l|l|l|}
\hline S. No & Property & Fine Aggregate & Coarse Aggregate \\
\hline 1. & Specific gravity & 2.42 & 2.6 \\
\hline 2. & Bulk Density Loose & $1545.69 \mathrm{~kg} / \mathrm{m}^{3}$ & $1400 \mathrm{~kg} / \mathrm{m}^{3}$ \\
\hline 3. & Bulking & $4 \% \mathrm{w} \mathrm{c}$ & -- \\
\hline 4. & Flakiness Index & -- & $8 \%$ \\
\hline 5. & Elongation Index & -- & $0 \%$ \\
\hline 6. & Fineness Modulus & 2.64 & -- \\
\hline
\end{tabular}

\subsubsection{Metakaolin}

Metakaolin differs from other supplementary cementitious materials (SCMs), like silica fume, fly ash, slag. For this work metakaolin was obtained from 20 microns Ltd, Mumbai

Table: 3 Physical properties of Metakaolin

\begin{tabular}{|l|l|l|l|}
\hline S.No & $\begin{array}{l}\text { Description of physical } \\
\text { properties }\end{array}$ & Units & Results \\
\hline 1 & Color & & 1Close To Std \\
\hline 2 & Appearance & & 1 OFF whitePowder \\
\hline 3 & Bulk Density & Gm/liter & 356 \\
\hline 4 & Specific gravity & & 2.63 \\
\hline
\end{tabular}

\subsubsection{Super Plasticizer}

The chemical admixture GLENIUM B233 was used a super plasticizer. The normal dosage of GLENIUM B233 is between 0.5 and 1.5 liters per $100 \mathrm{~kg}$ cementitious material. Dosages outside this range are permissible subjected to trial mixes.

Table: 4 Properties of Super plasticizer

\begin{tabular}{|l|l|l|}
\hline S. No & Property & Results \\
\hline 1. & Form or state & Liquid \\
\hline 2. & Color & Brown \\
\hline 3. & Specific Gravity & 1.09 at $30^{\circ} \mathrm{C}$ \\
\hline
\end{tabular}

\subsubsection{Water}

As per recommendation of IS: 456 -2000, the water used for mixing and curing must be clean and free from substances that may be deleterious to concrete or steel The $\mathrm{pH}$ value of water shall be not less than 6 . In the present investigation, tap water is used for both mixing and curing purposes. ${ }^{[10]}$ 


\subsection{Mix Proportions For M40 SCC (Metakoalin \% Variable)}

SCCMK 20: Cement replaced by $20 \%$ of Metakaolin

SCCMK 22: Cement replaced by $22 \%$ of Metakaolin

SCCMK 24: Cement replaced by $24 \%$ of Metakaolin

SCCMK 26: Cement replaced by $26 \%$ of Metakaolin

SCCMK 28: Cement replaced by $28 \%$ of Metakaolin

SCCMK 30: Cement replaced by $30 \%$ of Metakaolin

SCCMK 32: Cement replaced by $32 \%$ of Metakaolin

SCCMK 34: Cement replaced by $34 \%$ of Metakaolin

SCCMK 36: Cement replaced by $36 \%$ of Metakaolin

SCCMK 38: Cement replaced by $38 \%$ of Metakaolin

Table: 5 Mix Proportions for M40 SCC

\begin{tabular}{|l|l|l|l|l|l|l|l|l|}
\hline MIX (\%) & $\begin{array}{l}\text { Cement } \\
(\mathrm{kgs})\end{array}$ & $\begin{array}{l}\text { Mk } \\
(\mathrm{kgs})\end{array}$ & $\begin{array}{l}\text { Powder } \\
(\mathrm{kgs})\end{array}$ & $\begin{array}{l}\text { Coarse Agg } \\
(\mathrm{kgs})\end{array}$ & $\begin{array}{l}\text { Fine Agg } \\
(\mathrm{kgs})\end{array}$ & $\begin{array}{l}\text { Water } \\
(\mathrm{lts})\end{array}$ & $\begin{array}{l}\text { Sp } \\
(\mathrm{lts})\end{array}$ & $\begin{array}{l}\text { Total (kgs) } \\
\text { SCCMK 20 }\end{array}$ \\
399.1 & 68.9 & 468 & 766 & 916 & 172 & 8.5 & 2330.5 \\
\hline SCCMK 22 & 392.21 & 75.79 & 468 & 766 & 916 & 172 & 8.5 & 2330.5 \\
\hline SCCMK 24 & 385.32 & 82.68 & 468 & 766 & 916 & 172 & 8.5 & 2330.5 \\
\hline SCCMK 26 & 378.43 & 89.57 & 468 & 766 & 916 & 172 & 8.5 & 2330.5 \\
\hline SCCMK 28 & 371.54 & 96.46 & 468 & 766 & 916 & 172 & 8.5 & 2330.5 \\
\hline SCCMK 30 & 364.65 & 103.35 & 468 & 766 & 916 & 172 & 8.5 & 2330.5 \\
\hline SCCMK 32 & 357.76 & 110.24 & 468 & 766 & 916 & 172 & 8.5 & 2330.5 \\
\hline SCCMK 34 & 350.87 & 117.13 & 468 & 766 & 916 & 172 & 8.5 & 2330.5 \\
\hline SCCMK 36 & 344.51 & 122.96 & 468 & 766 & 916 & 172 & 8.5 & 2330.5 \\
\hline SCCMK 38 & 338.20 & 129.79 & 468 & 766 & 916 & 172 & 8.5 & 2330.5 \\
\hline
\end{tabular}

\section{Results And Discussion}

Test methods include the tests of fresh concrete mix for workability and hardened concrete specimens for compressive and split tensile strength, flexural strength test. Various tests were conducted on the trail mixes to ensure the requirement of filling ability, passing ability, segregation. The test mentioned in Table 6 was conducted to assess whether the mixes meet the workability requirements of SCC. The results of tests conducted on fresh concrete are given in Table 6.

\subsection{Workability Tests}

Table 6: Fresh properties of M40 SCC

\begin{tabular}{|c|c|c|c|c|c|c|}
\hline \multirow[t]{2}{*}{ Concrete Mixes } & \multicolumn{2}{|c|}{ Slump Flow } & \multicolumn{2}{|c|}{ V-Funnel } & \multirow{2}{*}{$\begin{array}{l}\text { L-Box } \\
\text { h2/h1 }\end{array}$} & \multirow{2}{*}{$\begin{array}{l}\text { U-Box } \\
\mathrm{mm}\end{array}$} \\
\hline & $\operatorname{Dia}(\mathrm{mm})$ & T500 (Sec) & Sec & $\begin{array}{l}T_{5} \\
(\mathrm{Sec})\end{array}$ & & \\
\hline SCCMK 20 & 638 & 4.2 & 11.2 & 14.4 & 0.68 & 3 \\
\hline SCCMK 22 & 657 & 4.56 & 11.85 & 14.63 & 0.76 & 4 \\
\hline SCCMK 24 & 669 & 4.9 & 12.2 & 15.54 & 0.81 & 5 \\
\hline SCCMK 26 & 685 & 5.2 & 12.54 & 15.69 & 0.87 & 6 \\
\hline SCCMK 28 & 697 & 5.5 & 12.74 & 15.87 & 0.93 & 7 \\
\hline SCCMK 30 & 700 & 6 & 12.9 & 16.06 & 0.96 & 8 \\
\hline SCCMK 32 & 698 & 5.93 & 12.63 & 15.84 & 0.9 & 7 \\
\hline SCCMK 34 & 695 & 5.78 & 12 & 15.75 & 0.85 & 6 \\
\hline SCCMK 36 & 680 & 5 & 11.67 & 14.8 & 0.78 & 5 \\
\hline SSCMK38 & 675 & 4.6 & 11.3 & 14.2 & 0.71 & 4 \\
\hline
\end{tabular}

\subsection{Compressive Strength Tests}

In this investigation, the cube specimens of size $100 \mathrm{~mm} \times 100 \mathrm{~mm} \times 100 \mathrm{~mm}$ are tested in accordance with IS: $516-1959$ [Method of test for strength of concrete]. The testing was done on a compression testing machine of 200 tons capacity. The machine has been calibrated to the required standards. Compressive strength tests were conducted on $100 \mathrm{~mm}$ size cubes of SCC in a compression testing machine at 7 and 28 days. The results are given in Table 7 and plotted in Fig. $1 .^{[11]}$

Table: 7 Compressive Strength Results

\begin{tabular}{|l|l|l|}
\hline \multirow{2}{*}{ Type Of Mix } & \multicolumn{2}{|l|}{$\begin{array}{l}\text { Compressive Strength } \\
(\mathrm{N} / \mathrm{mm} 2)\end{array}$} \\
\cline { 2 - 3 } & 7 days & 28 days \\
\hline SCCMK 20 & 33.82 & 48.31 \\
\hline SCCMK 22 & 34.66 & 49.52 \\
\hline SCCMK 24 & 35.32 & 50.46 \\
\hline SCCMK 26 & 35.65 & 51.08 \\
\hline
\end{tabular}




\begin{tabular}{|l|l|l|}
\hline SCCMK 28 & 36.28 & 51.84 \\
\hline SCCMK 30 & 36.91 & 52.74 \\
\hline SCCMK 32 & 35.67 & 50.95 \\
\hline SCCMK 34 & 34.95 & 49.94 \\
\hline SCCMK 36 & 33.76 & 47.68 \\
\hline SCCMK 38 & 31.74 & 44.81 \\
\hline
\end{tabular}

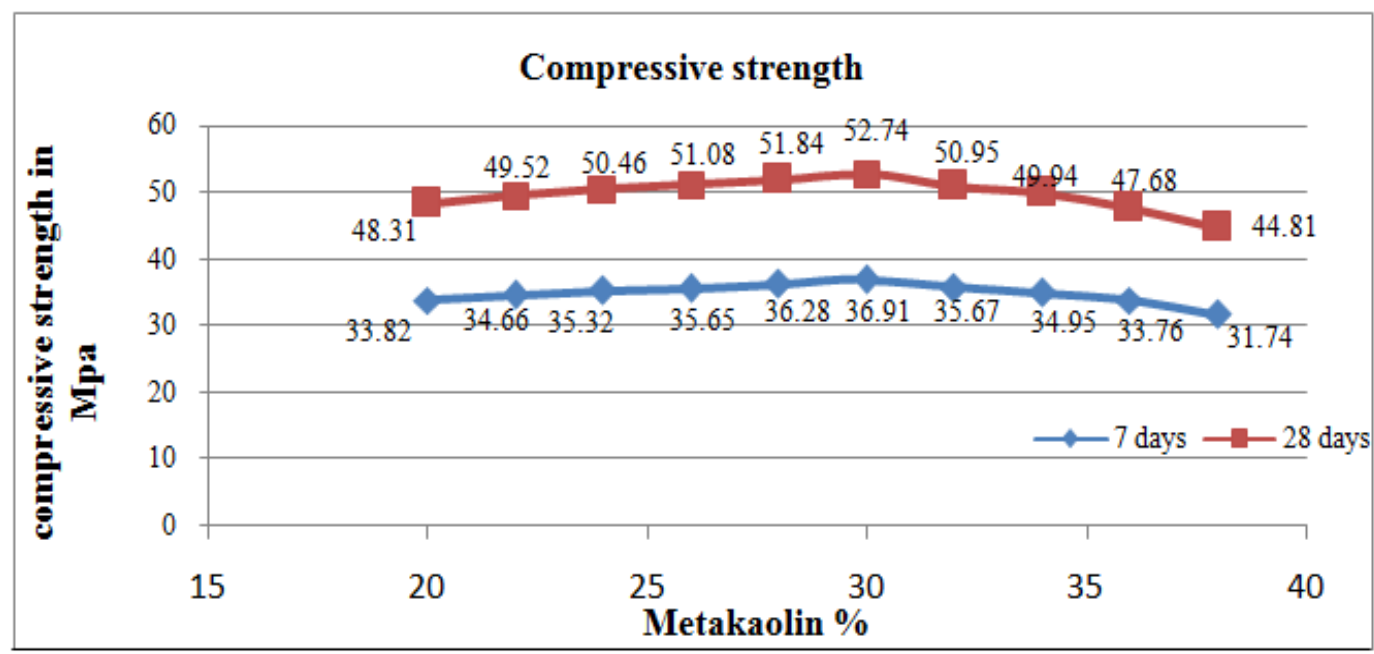

Figure 1 metakaolin\% vs compressive strength

\subsection{Split Tensile Strength Tests}

Splitting tensile strength tests were conducted on cylindrical specimens of $150 \mathrm{~mm}$ diameter and $300 \mathrm{~mm}$ height at 7 and 28 days in accordance with BIS specifications and procedures. The results are given in Table 8 .

Table 8 Split Tensile Strength results

\begin{tabular}{|l|l|l|}
\hline \multirow{2}{*}{ Type Of Mix } & \multicolumn{2}{|l|}{ Split tensile strength $\left(\mathrm{N} / \mathrm{mm}^{2}\right)$} \\
\cline { 2 - 3 } & 7 days & 28 days \\
\hline SCCMK 20 & 3.42 & 4.16 \\
\hline SCCMK 22 & 3.49 & 4.23 \\
\hline SCCMK 24 & 3.53 & 4.3 \\
\hline SCCMK 26 & 3.58 & 4.38 \\
\hline SCCMK 28 & 3.61 & 4.41 \\
\hline SCCMK 30 & 3.65 & 4.49 \\
\hline SCCMK 32 & 3.58 & 4.39 \\
\hline SCCMK 34 & 3.53 & 4.34 \\
\hline SCCMK 36 & 3.46 & 4.28 \\
\hline SCCMK 38 & 3.34 & 4.08 \\
\hline
\end{tabular}

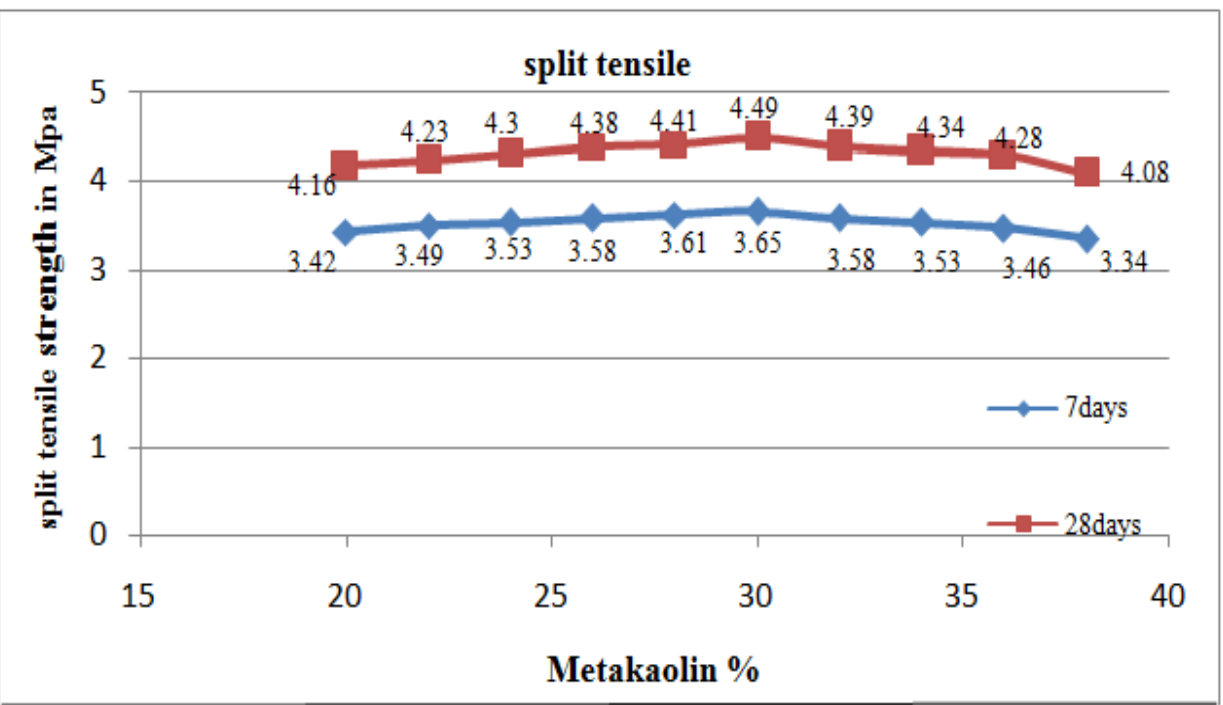

Figure 2Metakaolin\% Vs Split tensile strength 


\section{4 Flexural Strength Tests}

Flexural tests were conducted on beams of size of $100 \mathrm{~mm}$ x 100mm X $500 \mathrm{~mm}$ subjected to two point loading at 28 days in UTM and the results were given in Table 9. These results are plotted in Fig.3.

Table: 9 Flexural Strength Results

\begin{tabular}{|l|l|l|}
\hline \multirow{2}{*}{ Type Of Mix } & \multicolumn{2}{|l|}{ Flexural strength $\left(\mathrm{N} / \mathrm{mm}^{2}\right)$} \\
\cline { 2 - 3 } & 7 days & 28days \\
\hline SCCMK 20 & 4.07 & 4.86 \\
\hline SCCMK 22 & 4.11 & 4.92 \\
\hline SCCMK 24 & 4.16 & 4.97 \\
\hline SCCMK 26 & 4.18 & 5.0 \\
\hline SCCMK 28 & 4.21 & 5.04 \\
\hline SCCMK 30 & 4.25 & 5.1 \\
\hline SCCMK 32 & 4.20 & 4.99 \\
\hline SCCMK 34 & 4.13 & 4.94 \\
\hline SCCMK 36 & 4.06 & 4.83 \\
\hline SCCMK 38 & 3.94 & 4.68 \\
\hline
\end{tabular}

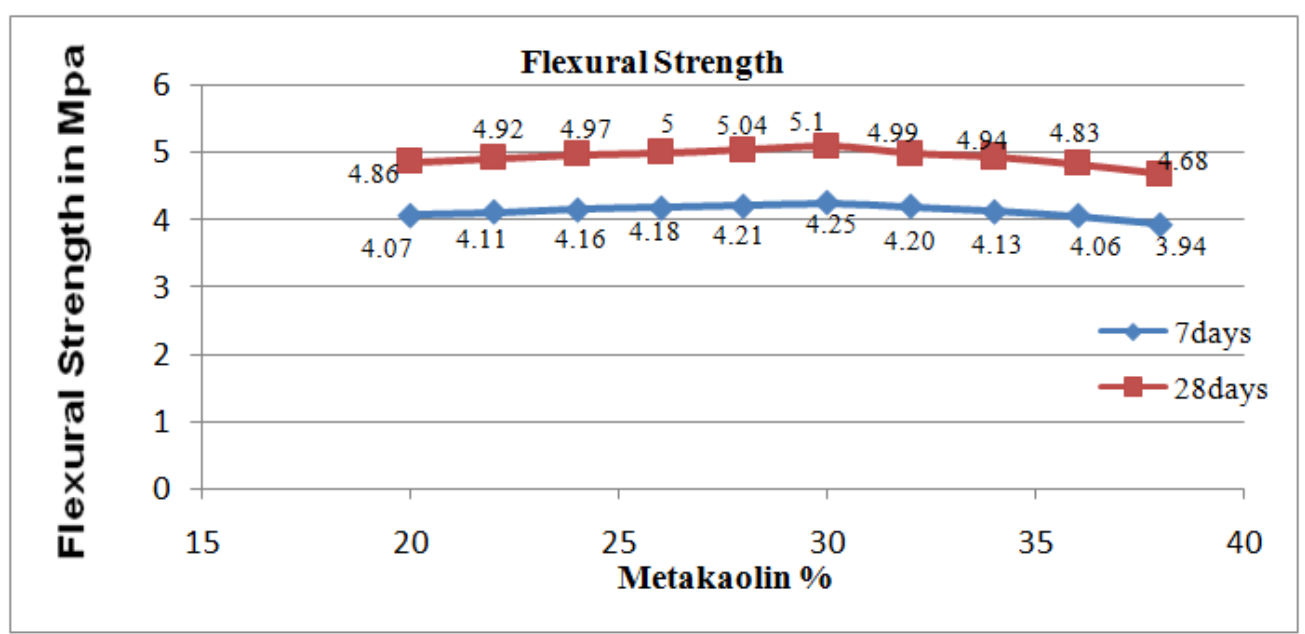

Figure 3 Metakaolin\% Vs Flexural strength

\subsection{Non Destructive Tests}

The main objective of the present experimental investigations is to assess the quality, structural integrity and estimated compressive strength of metakaolin incorporated self compacting concrete of grade M40 using Rebound hammer and Ultrasonic pulse velocity measurements.

\subsubsection{Rebound Hammer Test}

Rebound hammer is the oldest technique used to assess the compressive strength of concrete indirectly and also to compare the various parts of structure. Schmidt rebound hammer is the instrument for this test. Schmidt rebound hammer shown in Fig1 is a simple, handy tool, which can be used to provide a convenient and rapid indication of the compressive strength of concrete. It consists of a spring controlled mass that slides on a plunger within a tubular housing. It works on the principle that the rebound of an elastic mass depends on the hardness of the surface against which the mass impinges.

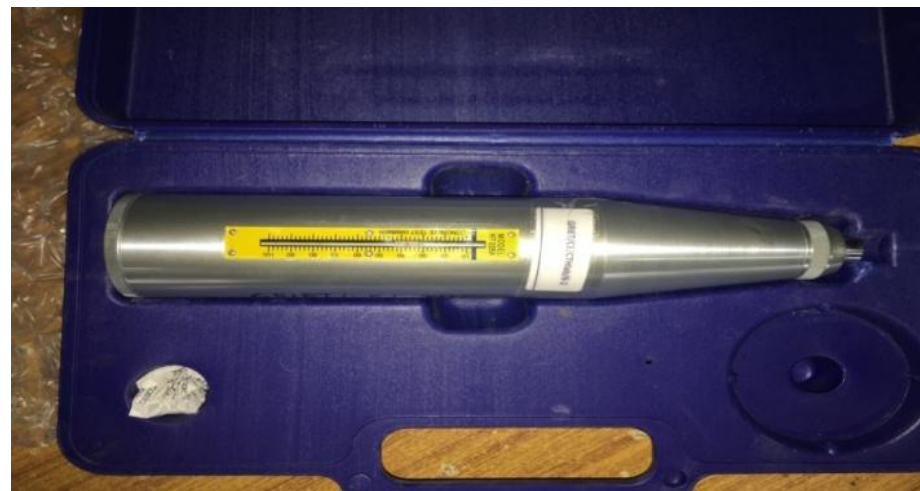

Figure 4: Rebound hammer used 
Table 10: Quality of concrete based on Average Rebound Hammer

\begin{tabular}{|l|l|}
\hline Average rebound number & Quality of concrete \\
\hline \multicolumn{1}{|c|}{$>40$} & Very good hard layer \\
\hline 30 to 40 & Good layer \\
\hline 20 to 30 & Fair \\
\hline$<20$ & Poor \\
\hline
\end{tabular}

\subsubsection{Ultrasonic Pulse Velocity Test}

Three reading of ultrasonic pulse velocity (USPV) were obtained for each cube. The cubes were then give a load of $7 \mathrm{~N} / \mathrm{mm} 2$ (as specified by the IS code 13311) in the compression testing machine and the USPV were obtained. The cubes were then loaded upto their ultimate stress and the breaking load was obtained. The method starts with the determination of the time required for a pulse vibration at an ultrasonic frequency to travel through a concrete. Once the velocity is determined, an idea about quality, uniformity, condition and strength of the concrete tested can be attained. In the test, the time the pulses take to travel through concrete is recorded. Then the velocity is calculated as ${ }^{[12]}$

$\mathbf{V}=\mathbf{L} / \mathbf{T}$

Where

$\mathrm{V}=$ Pulse Velocity, $\mathrm{L}=$ travel time in meters and

$\mathrm{T}=$ effective time in seconds

Table: 11 General Guidelines for Concrete Quality based on USPV

\begin{tabular}{|l|l|}
\hline Pulse Velocity & Quality of concrete \\
\hline $4.0 \mathrm{~km} / \mathrm{s}$ & Very good to excellent \\
\hline 3.5 to $4.0 \mathrm{~km} / \mathrm{s}$ & Good to very good, slightly porosity may exist \\
\hline 3.0 to $3.5 \mathrm{~km} / \mathrm{s}$ & Satisfactory but loss of integrity may exist \\
\hline$<3.0 \mathrm{~km} / \mathrm{s}$ & Poor and loss of integrity exist \\
\hline
\end{tabular}

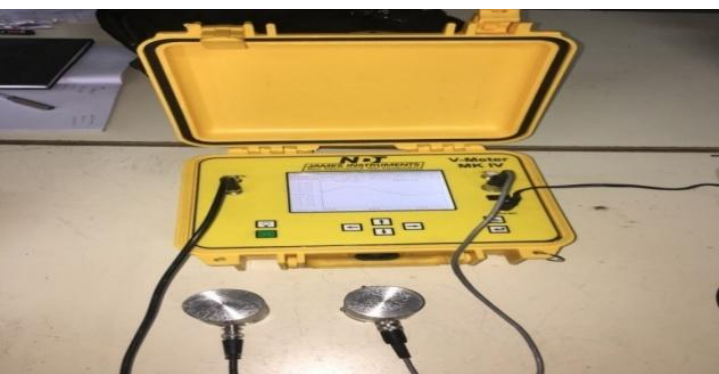

Figure 5: Ultrasonic Pulse Velocity used

Table: 12 Non-destructive test results of M40 grade SCC

\begin{tabular}{|l|l|l|l|l|}
\hline \multirow{3}{*}{$\%(\mathrm{MK})$} & \multicolumn{4}{l}{ Combined Rebound hammer and Ultrasonic Pulse Velocity Methods Results } \\
\cline { 2 - 5 } & M40 Concrete, Mpa & $\begin{array}{l}\text { Mean Pulse Velocity } \\
\mathrm{km} / \mathrm{sec}\end{array}$ & $\begin{array}{l}\text { Compressive } \\
\text { Strength N/mm2 }\end{array}$ & Quality of Concrete \\
\cline { 2 - 5 } & Mean Rebound Value & 2.83 & 23.3 & Satisfactory \\
\hline $20 \%$ & 29.6 & 2.98 & 26.5 & Satisfactory \\
\hline $22 \%$ & 31.9 & 3.08 & 30 & Medium \\
\hline $24 \%$ & 34.2 & 4.37 & 35.5 & Good \\
\hline $26 \%$ & 36.7 & 4.48 & 43.7 & Good \\
\hline $28 \%$ & 41.4 & 5.27 & 50.4 & Excellent \\
\hline $30 \%$ & 43.9 & 4.93 & 48.1 & Excellent \\
\hline $32 \%$ & 42.7 & 4.24 & 37.5 & Good \\
\hline $34 \%$ & 38.2 & 3.3 & 31.8 & Medium \\
\hline $36 \%$ & 35.1 & 2.37 & 24.9 & Satisfactory \\
\hline $38 \%$ & 32.5 & & & \\
\hline
\end{tabular}

\section{Conclusion}

From the detailed experimental work done on SCC mix with an aim to study on properties of fresh and hardened self compacting concrete with varied percentages of metakaolin as mineral admixture for M40 grade $(20 \%, 22 \%, 24 \%, 26 \%, 28 \%, 30 \%, 32 \%, 34 \%, 36 \% \& 38 \%)$ the following conclusions are arrived.

The workability increases gradually as the percentage increases from $20 \%$ to $30 \%$ and decreases from $32 \%$ to $38 \%$.

> The compressive strength, split tensile strength and flexural strength increased with the increase in the percentage of metakaolin from $20 \%$ to $30 \%$ \& decreased from $32 \%$ to $38 \%$.

$>$ The optimum percentage of metakaolin is taken as $30 \%$ for $\mathrm{w} / \mathrm{c}=0.38$. 
$>$ Based on the Non Destructive Tests it is concluded that quality of concrete,

- For the mix with $30 \%$ \& $32 \%$ metakaolin is excellent.

- For the mix with $26 \%, 28 \%$ \& $34 \%$ metakaolin is good.

- For the mix with $24 \& 36 \%$ metakaolin is medium.

- For the mix with $20 \%, 22 \%, 38 \%$ metakaolin is satisfactory

\section{References}

[1] Okamura.H., and Ouchi.M., (2003) "Self-compacting concrete", Journal of Advanced Concrete Technology, 1[ 1], 5-15.

[2] Justice. J.M., Kennison. L.H., Mohr.B.J., Beckwith. S.L., McCormick. L.E., Wiggins. B., Zhang.Z. Z., and Kurtis. K.E., (2005) "Comparison of Two Metakaolins and a Silica Fume Used as Supplementary Cementitious Materials" International Symposium in Washington D.C. 20-24,

[3] Karjinni. Vilas V., Anadinni. Shrishail B., (2009) "Mixture Proportion Procedure for SCC" Indian Concrete Journal. 35-41.

[4] Sabir. B.B., wild. S, Bhai. J., (2001) "Metakaolin and calcined clays as a pozzolans for concrete: a review" cement and concrete composites 441-454.

[5] Subramanian .S., and Chatopadyay.D., (2002)“Experiments for mix proportions of Self Compacting Concrete", The Indian Concrete journal, 13-20

[6] Naveen Kumar C., Jagadish V., and Ranganath R.V., ( 2006) "Self-Compacting Concrete with Fly Ash and Metakaolin", The Indian Concrete Journal, 33-39.

[7] Mallikarjuna Reddy .V., Seshagiri Rao. M.V., Srilakshmi. P., and Venkateswarlu. K., "Effect of Packing Factor on workability and Mechanical Properties of Self-Compacting Concrete of M70 Grade with Fly Ash and Micro Silica as filler Material".

[8] IS 12269:2013 Ordinary Portland Cement, 53 grade - specification (first revision), Bureau of Indian Standards, New Delhi

[9] IS: 383 (Specification for coarse and fine aggregates from natural sources for concrete), Indian Standard Code of Practice, 1970.

[10] IS: 456 - 2000 Plain and reinforced concrete - Code of practice (fourth revision), Bureau of Indian Standards, New Delhi

[11] IS: $516-1959$ [Method of test for strength of concrete].

[12] IS13311 (Part1 )- 1992 [method of test for ultrasonic pulse velocity]

[13] www.efnarc.org:European Specifications and guidelines for Production \& Use of SCC, February and May 2005.

[14] EFNARC guidelines for Specifications and guidelines for Self-compacting concrete, February 2002

[15] www.basf-cc.co.in. (Gelenium). 